\title{
Epidemiological profile of leishmaniasis at a reference service in the state of Alagoas, Brazil, from January 2000 to September 2008
}

Authors

Willian da Silva Nunes Sócrates Rios Araújo ${ }^{1}$ Cláudia Maria Lins Calheiros ${ }^{2}$

${ }^{1}$ Medical Student. ${ }^{\star}$ ${ }^{2}$ Medical School Professor.

*UNCISAL, Maceió, AL Brazil.
Submitted on: 05/03/2010 Approved on: 18/03/2010

Correspondence to: Willian da Silva Nunes Universidade Estadual de Ciências da saúde de Alagoas - UNCISAL

Faculdade de Medicina. Rua Dr. Jorge de Lima, 113, Trapiche da Barra,

Maceió - Alagoas - Brazil CEP: $57010-382$

Phone: +55-82-32218538

E-mail: willian

medicina@hotmail.com

We declare no conflict of interest.

\begin{abstract}
Leishmaniasis is a parasitic disease found in the continents of Europe, Asia, Africa and the Americas. In Brazil, the disease is an important public health problem, occurring in most states, but mainly in the Northeast region of the country, with the state of Alagoas having a significant number of confirmed cases.

The present study establishes and discusses the epidemiological profile of cases of leishmaniases treated at the Reference Center of Alagoas, Hospital Escola Hélvio de Farias Auto, between January 2000 and October 2008. During thisperiod, records of 2,104 patients notified to the hospital Epidemiological Surveillance Center were reviewed. The epidemiology of leishmaniasis, both visceral and tegumentary, has shown a profile that has changed over throughout the years, with a decrease in the number of notified cases. Disease occurrence was associated with lower social economic classes, and affected mainly rural workers in general, housewives and students.
\end{abstract}

Keywords: American tegumentary leishmaniasis, visceral leishmaniasis, epidemiology.

[Braz J Infect Dis 2010;14(4):342-345]@Elsevier Editora Ltda.

\section{INTRODUCTION}

Leishmaniasis is a disease caused by protozoan parasites of the Leishmania genus, transmitted to man by the bite of an insect of the Lutzomyia genus, known as sand-fly. The disease has different clinical forms, ranging from a skin ulcer, which can heal spontaneously, to the most severe form of leishmaniasis, the visceral form, which can lead to patient's death when untreated (WHO, 1990). According to the location and species of the etiologic agent, leishmaniasis is classified as American tegumentary leishmaniasis (ATL), or visceral leishmaniasis (VL), also known as Kala-azar. Several forms of the disease have been reported in the continents of Europe, Asia, Africa and the Americas. Due to its frequency and lethality, mainly in untreated patients, it is currently among the six endemic diseases considered as priorities worldwide (WHO, 1990; BRASIL, 2003). Brazil is among the five countries with the largest number of cases of leishmaniasis, which represents an important public health problem, especially in the North, Midwest and Northeast regions of the country (COSTA, 2005). In recent years, an increase in the number of this parasitic disease has been observed in residential or peri-residential areas, especially in the Northeast region, where socioeconomic factors - such as housing conditions, poverty, migration process and lack of basic sanitation - favor the spread of disease expansion (Brasil, 2003; Costa, 2005; Lainson, 1978).

In Brazil, the number of cases has been increasing, both in magnitude and geographic expansion. Two distinct epidemiological profiles can be observed, expressed as the maintenance of cases that originated from old sources and surrounding areas, or by the onset of outbreaks associated with factors such as the accelerated expansion process of agricultural frontiers, the implementation of prospecting areas, road constructions and invasion of the city-outskirt areas, among several others. From 1985 to 1999, a total of 388,155 autochthonous cases of ATL were notified in the country. In this time period, the coefficient of ATL detection in Brazil has increased from 10.45/100,000 inhabitants to $18.63 / 100,000$ inhabitants, probably as a result of an improvement in disease notification in the country (BRASIL, 2000).

According to the Department of Informatics of the Brazilian Public Health System (SUS), DATASUS, a total of 33,872 cases of ATL per year were notified in Brazil from 1999 to 2003. The disease has been reported in all states, and has spread to new geographic areas, with 169,361 cases notified 
in the period. The Southern region reported the lowest number of cases $(3,952)$, whereas the Northern region had the highest burden of cases $(61,339)$ during the described period, with incidence rates per 100,000 inhabitants between 114.8 and 163.5. In the Amazon region, 12,005 cases have been notified in the same period, with mean incidence rates of 86.77 ; in the year 2003 , the incidence rate reached 121.03 , when 3,174 cases were reported, $60.18 \%$ occuring in the city of Manaus, state of Amazonas, Brazil (BRASIL, 2005).

According to the Ministry of Health, throughout 19 years of notification, the number of VL cases totaled 48,455 , with approximately $66 \%$ of them occurring in the states of Bahia, Ceará, Maranhão and Piauí. In the last ten years, the mean annual number of cases in the country was 3,156, and the incidence was of $2 / 100,000$ inhabitants. The disease is more frequent among children $<10$ years $(54.4 \%)$, with $41 \%$ of the cases being recorded in children $<5$ years. Men is proportionally more affected (60\%).

By having access to reliable data on this matter, the governmental institutions are aware that leishmaniasis is an important public health problem in our country and can prioritize disease prevention and control measures.

The present article describes the epidemiological profile of leishmaniasis cases treated in the state of Alagoas, taking into account a high prevalence between 2000 and 2002, followed by a decrease between 2003 and 2008, as demonstrated in Charts 1 and 2.

Chart 1: Cases of visceral leishmaniasis notified annually.

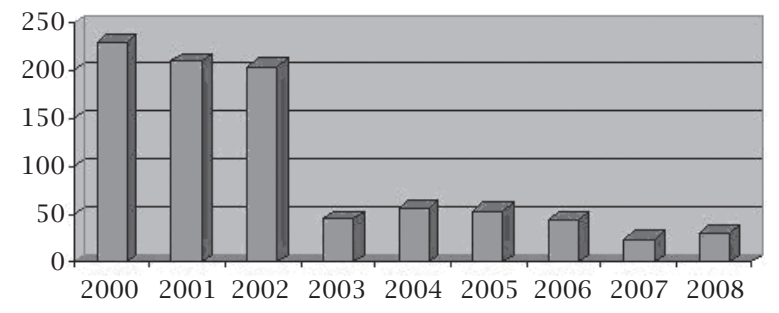

Source: Epidemiological Surveillance Center of Hospital Escola Hélvio Auto

Chart 2: Cases of tegumentary leishmaniasis notified annually.

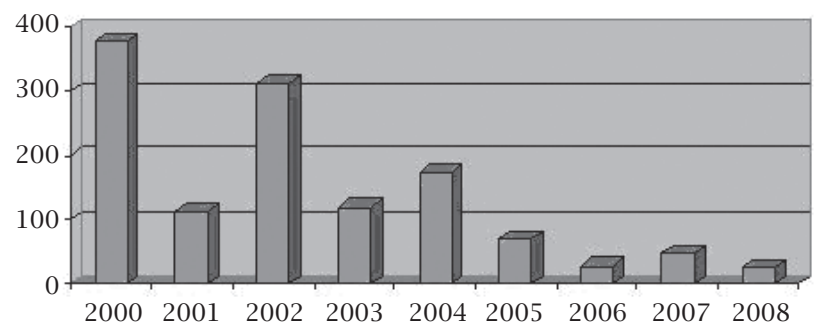

Source: Epidemiological Surveillance Center of Hospital Escola Hélvio Auto

\section{MATERIAL AND METHODS}

The present study was a retrospective review of medical records of 2,104 cases diagnosed with VL or ATL notified to the Epidemiological Surveillance Center of the University Hospital Dr. Hélvio de Farias Auto (HEHA), in the city of Maceió, state of Alagoas, Brazil, from January 2000 to October 2008.

The following patient variables were analyzed: age, sex, city of residence, occupation, clinical manifestations, diagnosis, administered drugs and case outcome.

Data were tabulated and analyzed through descriptive statistics in a Microsoft Excel spreadsheet, release 2003. The study was approved by the Research Ethics Committee of Universidade Estadual de Ciências da Saúde de Alagoas CEP/UNCISAL, process \# 1007.

\section{RESULTS}

During the period of January 2000 to October 2008, a total of 2,104 cases of leishmaniasis were diagnosed, of which 1,293 were ATL and 811 were VL.

The highest concentration (23.7\%) of reported cases was at the capital city Maceió $(\mathrm{n}=302)$, followed by $11.2 \%$ in the city of Joaquim Gomes ( $\mathrm{n}=142), 5.5 \%$ at União dos Palmares $(\mathrm{n}=70)$, and $4.4 \%$ at Chã Preta $(\mathrm{n}=56)$. Fiftyfive cities/towns did not report any case of ATL. Regarding VL, the city with the highest number of reported cases was Santana do Ipanema $(\mathrm{n}=59)$ with $7.9 \%$, followed by $5.6 \%$ at Palmeira dos Indios $(n=42), 5.5 \%$ at Traipu $(n=41)$, and $5.5 \%$ at São José da Tapera $(\mathrm{n}=41)$. Twenty-three cities/ towns did not report any case of VL.

In the period of 2000 to 2002 the highest number of cases was reported, with 546 cases of VL and 804 cases of ATL, corresponding to $64 \%$ of the total period between 2000 and 2008 (Table 1).

\section{Table 1. Number of cases}

\begin{tabular}{lcc}
\hline Year & VL & ATL \\
\hline 2000 & 230 & 378 \\
\hline 2001 & 211 & 112 \\
\hline 2002 & 105 & 314 \\
\hline 2003 & 46 & 119 \\
\hline 2004 & 56 & 175 \\
\hline 2005 & 54 & 70 \\
\hline 2006 & 45 & 49 \\
\hline 2007 & 25 & 26 \\
\hline 2008 & 31 & 46 \\
\hline Total & 811 & 1293 \\
\hline
\end{tabular}

Source: Epidemiological Surveillance Center of the University Hospital Hélvio Auto 
Sixty-three percent were male among the 823 cases with ATL, and $58.8 \%$ among the 477 VL cases.

The majority of the ALT cases were in the age ranges of cases $0-12$ (19,8\%) and 19-45 years (42.4\%); among LV cases, $67.4 \%$ and $13.5 \%$ were in the age ranges of $0-12$ and $19-30$ years, respectively. There were only $6.8 \%$ of the leishmaniasis cases reported in patients over 61 years old.

Regarding occupation, students had the highest rate of ATL infection, with $25.8 \%(\mathrm{n}=145)$, followed by housewives with $29.2 \%(\mathrm{n}=164)$; as for VL, rural workers had the highest rate, with $6.2 \%(n=51)$, followed by students, with $5.4 \%(n=44)$.

All cases presented a clinical picture indicative of the disease. Most ATL cases presented skin lesions as the only manifestation of the disease (Table 2). Among VL cases, symptoms such as fever $(n=673)$, splenomegaly $(n=681)$ and hepatomegaly $(\mathrm{n}=637)$ were the most clinical features (Tables 2 and 3$)$.

Indirect immunofluorescence assay (IFA) turned out positive in $37.1 \%(n=301)$, whereas parasitological tests were positive in $47.1 \%(\mathrm{n}=382)$ Among ATL cases, the Montenegro skin test (MST) had a positive result more often $56.1 \%$ than the parasitological tests $(9.3 \%)$. The low percentage of the parasitological tests for the diagnosis of ATL resulted in a high number of patients that were not submitted to the method.

Ninety-five percent of both ATL and VL patients were treated primarily with pentavalent antimony $(\mathrm{n}=1757)$, whereas Amphotericin b $(\mathrm{n}=91)$ was used by $4.9 \%$. The remaining $0.1 \%$ received other drugs, such as pentamidine and liposomal Amphotericin b.

Of the 1,293 cases of ATL, 576 were reassessed and discharged due to clinical cure, 21 abandoned treatment, 30 died due to ATL, and 99 died due to other causes.

Of the 811 cases of VL, 379 were reassessed and discharged due to clinical cure, 80 died due to LV and 271 were referred to another service.

Table 2. Clinical presentation of ATL cases

\begin{tabular}{lcc}
\hline Lesion & Total & \% \\
\hline Skin & 683 & 52.8 \\
\hline Mucosa & 94 & 7.2 \\
\hline
\end{tabular}

Source: Epidemiological Surveillance Center of Hospital Escola Hélvio Auto

Table 3. Clinical symptoms among VL cases

\begin{tabular}{lcc}
\hline Symptoms & Number & \% \\
\hline Fever & 675 & 83.3 \\
\hline Weakness & 312 & 38.51 \\
\hline Weight loss & 259 & 31.9 \\
\hline Coughing & 235 & 26.9 \\
\hline Splenomegaly & 681 & 84 \\
\hline Hepatomegaly & 637 & 89.8
\end{tabular}

Source: Epidemiological Surveillance Center of Hospital Escola Hélvio Auto

\section{DISCUSSION}

The number of cases of leishmaniasis in Brazil continue to increase, despite the actual incidence of the disease be probably underestimated, as the disease spread to new geographic areas, (Brasil, 2003; Brasil, 2007).

There has been a remarkable decrease in the number of notified cases for the state of Alagoas, Brazil, in the last four years, which contradicts the growth trend in Brazil, although the number of cases is still elevated.

The cities/towns in the state of Alagoas with the highest incidence of ATL cases were Maceió, Joaquim Gomes, União dos Palmares, and Chã Preta. The disease outbreak in the capital city, Maceió, might have been associated to the urban expansion as a result of deforestation and preservation of small circumscribed areas of residual forest, ciliary forest and those resulting from reforesting (Corte AA, 1996). The cities/towns with the highest incidence of VL cases were Santana do Ipanema, Palmeira dos Indios, Traipu and São José da Tapera. In this case, there was a more homogenous distribution of cases.

Women, children, urban-area dwellers and individuals whose occupations do not necessarily require entering the wooded areas more frequently to acquire the disease suggest this possibility, as proposed by other studies (Follador, 1999; Nunes, 2006; Guerra, 2006). The reason for the higher susceptibility presented by children could be explained by the state of relative immaturity of cellular immunity, aggravated by malnutrition, which is very common in the endemic areas, in addition to a higher level of exposure to the disease vector in the peri-residential areas. The present study showed a male predominance among cases, differently from what has been reported elsewhere. Occupations, such as students and housewives were disproportionately represented among cases, as they tend to have close contact to domestic animals, typical hosts of the disease.

Practically all cases presented typical signs of the disease, with fever, splenomegaly and hepatomegaly being the most frequently reported clinical findings in VL. Splenomegaly, which in some series was present in all patients, was observed in $83.9 \%$ of the cases in the present study, in accordance to other authors who reported splenomegaly in 2 to $18 \%$ of the cases (Cascio A, 2002; Cole ACE, 1944). The predominance in exposed areas of the body and the ulcerated aspect correspond to the most frequent description of the skin lesions in ATL (Chiari CA, 1973). In the present study, the cutaneous form was most frequently observed in ATL.

The diagnosis of ATL, both cutaneous and mucosal forms, is eminently clinical, supplemented by subsidiary laboratory tests, such as direct analysis of material scraped or aspirated from the lesion, stained by Giemsa's or Leishman's stain, histopathological examination (HE) 
of lesion biopsy, the Montenegro skin test (MST) and the indirect immunofluorescence assay (IFA) (Davies CR, 2003; Silveira FT, 2004). The most frequently used methods in ATL were IFA followed by the parasitological test. In VL, IFA and the parasitological test were used more often, contributing equally to the diagnosis.

The $\mathrm{N}$-methyl-glucamine antimoniate (Glucantime ${ }^{\circledR}$ ) is the only pentavalent formulation commercialized in Brazil. It is presented in 5- $\mathrm{mL}$ ampoules containing $1.5 \mathrm{~g}$ of raw antimoniate, equivalent to $425 \mathrm{mg}$ of Sb5+; therefore, each mL contains $85 \mathrm{mg}$ of Sb5+ (FUNASA, 2000). Other drugs, such as sulphas, ketoconazole, allopurinol, aminosidine and Amphotericin B are alternative therapies. In addition to patient adherence, treatment success depends on the time elapsed from diagnosis to initiation of therapy (Passos, 2000). The present study pentavalent antimony was the treatment of choice for both ATL and $\mathrm{VL}$, followed by Amphotericin B in a minority of patients.

In the present study the cure rate was less than $50 \%$ for the two clinical forms of leishmaniasis. Additionally, there was no information regarding patient outcome available in the medical records. Death due to leishmaniasis could be explained by delayed initiation of therapy.

\section{CONCLUSION}

Leishmaniasis is a disease that has accompanied mankind since ancient times. There has been an increase in the number of cases in the last 20 years, as well as expansion new geographic areas.

Currently, the disease is an important public health problem and represents a challenge for health professionals. Epidemiological studies might help planning for effective strategies to control VL and ATL. To this end, a better control of the canine population and surveillance strategies must be intensified.

The scarcity of investments in public health in the country, especially in preventive measures, aggravated by the fact that Brazil is located in a tropical region, of which climate is favorable to the development of several endemic diseases, contribute to maintain leishmaniasis as an important public health problem in the country.

\section{REFERENCES}

1. Brasil. Ministério da Saúde. Secretaria de Vigilância em Saúde. Departamento de Vigilância Epidemiológica. Manual de controle da leishmaniose tegumentar americana. Brasília; 2003. p. 7-29.

2. Brasil. Ministério da Saúde. Secretária de Vigilância em Saúde. Tópicos de Saúde - L: Leishmaniose visceral. Leishmaniose tegumentar americana. Brasília; 2007. Accessed from [http:// www.portal.saude.gov.br].

3. Corte AA, Ferreira MC, Felipe PAN et al. Aspectos ecoepidemiológicos da LTA no município de Campinas. Cad Saúde Pública 1996; 12:465-72.

4. Follador I, Araujo C, Cardoso MA et al. Surto de leishmaniose tegumentar americana em Canoa, Santo Amaro, Bahia, Brasil. Rev Soc Bras Med Trop 1999; 32: 497-503.

5. Nunes AG, Paula EV, Teodoro R, Prata A, Silva-Vergara ML. Aspectos epidemiológicos da leishmaniose tegumentar americana em Varzelândia, Minas Gerais, Brasil. Cad Saúde Pública 2006; 22:1343-7.

6. Guerra JAO, Ribeiro JAS, Coelho LIARC, Barbosa MGV, Paes MG. Epidemiologia de leishmaniose tegumentar na Comunidade São João, Manaus, Amazonas, Brasil. Cad Saúde Pública 2006; 22:2319-27.

7. Cascio A, Colomba C, Antinori S, Orobello M, Paterson D, Titone L. Pediatric visceral leishmaniasis in Western Sicily, Italy: a retrospective analysis of 111 cases. Eur J Clin Microbiol Infect Dis 2002; 21:277-82.

8. Cole ACE. Kala-azar in East África. Trans R Soc Trop Med Hyg 1944; 37:409.

9. Chiari CA, Mayrink W, Magalhães PA. Reação de imunofluorescência indireta no controle do tratamento da leishmaniose tegumentar americana. Revista do Instituto de Medicina Tropical de São Paulo 1973; 15:298-303.

10. Davies CR, Kaye P, Croft SL, Sundar S. Leishmaniasis: new approaches to disease control. BMJ 2003; 326:377-82.

11. Silveira FT, Lainson R, Corbett CEP. Clinical and immunopathological spectrum of American Cutaneous Leishmaniasis with special reference to the disease in Amazonian Brazil - A review. Mem Inst Oswaldo Cruz 2004; 99:239-51.

12. FUNASA, Ministério da Saúde. Fundação Nacional de Saúde. Manual de controle da Leishmaniose Tegumentar Americana, 2000. 65 p.

13. Passos VMA, Barreto SM, Romanha AJ, Krettii AU, Volpini AC, Costa MFFL. American cutaneous leishmaniasis: use of a skin test as a predictor of relapse after treatment. Bull World Health Organ 2000; 78:968-74.

14. World Health Organization. Control of the Leishmaniasis. Geneva: WHO (Technical Report Series 703); 1990. p. 79-87.

15. Costa JML. Epidemiologia das leishmanioses no Brasil. Gazeta Médica da Bahia 2005;75:3-17.

16. Lainson R, Shauw JJ. Epidemiology and ecology of leishmaniasis in Latin America. Nature 1978; 273:596-600. 